\title{
O TRABALHO DOS AGENTES COMUNITÁRIOS DE SAÚDE: ENTRE A MEDIAÇÃO CONVENCEDORA E A TRANSFORMADORA
}

THE WORK OF COMMUNITY HEALTH AGENTS: BETWEEN CONVINCING AND TRANSFORMING MEDIATION

\author{
Vera Joana Bornstein ${ }^{1}$ \\ Eduardo Navarro Stotz ${ }^{2}$
}

Resumo Este artigo busca caracterizar as diferentes formas de mediação presentes no cotidiano do trabalho do agente comunitário de saúde - elemento inovador no quadro funcional da Estratégia Saúde da Família -, as quais oscilam entre o convencimento e a transformação. Considera que a função mediadora desempenhada pelos agentes pode ser de grande importância na mudança do modelo assistencial, na medida em que assuma um caráter transformador, e entende a educação popular como um caminho para o fortalecimento desta forma de mediação e para a mudança do modelo assistencial. O estudo possibilitou o conhecimento das práticas dos agentes comunitários de saúde e permitiu apontar questões consideradas fundamentais para que o modelo assistencial possa corresponder às necessidades e expectativas da população e se aproximar dos princípios de integralidade, eqüidade, humanização e participação popular.

Palavras-chave agente comunitário de saúde; saúde da família; atenção primária à saúde; mediação.
Abstract This article seeks to characterize the different forms of mediation present in the daily work of the community health agent - an innovative element in the functional framework of the Family Health Strategy -, which oscillate between convincement an transformation. It believes that the mediating role the agents have can be of major importance to change the assistential model as it takes-on a transforming character, and sees popular education as a path towards strengthening this type of mediation and to change the assistential model. The study allowed community health agent practices to be known and to point to issues that are considered as fundamental in order for the assistential model to be able to meet the needs and expectations of the population and come closer to the principles of integrality, equity, humanization and popular participation.

Keywords community health agent; family health; primary health care; mediation. 


\section{Introdução}

A partir de 1997, o Programa de Agentes Comunitários de Saúde (Pacs) e o Programa Saúde da Família (PSF) passaram a ser prioridades do Plano de Metas do Ministério da Saúde. Documentos oficiais enfatizam a importância da estratégia Saúde da Família na reorientação do modelo de atenção a partir da Atenção Básica e, ao mesmo tempo, consideram que esta estratégia pode imprimir nova dinâmica de organização dos serviços e ações de saúde. Sustenta-se que o modelo procura agir sobre as necessidades em saúde, atuando preventivamente ao invés de esperar a demanda espontânea orientada para a cura de doenças e medicocentrada.

Ambos os programas têm em comum e como elemento inovador no quadro funcional a figura do agente comunitário de saúde (ACS), sobre o qual recaem expectativas de mediação, aproximação, facilitação do trabalho de atenção básica em saúde. Daí a importância de aprofundar o estudo sobre a forma como se dá a mediação realizada pelo ACS.

Na equipe de saúde, o agente comunitário é o trabalhador que se caracteriza por ter o maior conhecimento empírico da área onde atua: a dinâmica social, os valores, as formas de organização e o conhecimento que circula entre os moradores. Esse conhecimento pode facilitar o trânsito da equipe, as parcerias e articulações locais. O reconhecimento destas características quer pelos profissionais, quer pelos moradores traduz-se em diferentes expectativas. De um lado, pela inserção nos serviços de saúde, espera-se dele o exercício de um papel de controle da situação de saúde da população; de outro, os moradores esperam que o agente facilite seu acesso ao serviço de saúde.

De maneira geral, o papel do agente comunitário como mediador é um consenso na literatura consultada por Bornstein e Stotz (2008) e tem sido abordado por vários autores e documentos oficiais. No entanto, falta deterse nesta mediação para examinar as diferentes formas em que ela se realiza no seu cotidiano de trabalho.

A mediação é entendida de diversas maneiras: pode ser vista como facilitação do acesso da população ao serviço; melhor estratégia para que as normas, objetivos e metas dos serviços sejam entendidos e assimilados pelas 'classes populares'; maneira de buscar nos serviços uma abertura para o entendimento da lógica e da dinâmica locais; e, ainda, mediação entre o conhecimento popular e o conhecimento tecnocientífico. Nogueira, Silva e Ramos (2000) ampliam o conceito de 'mediação', quando apontam que a função de 'ponte' pode ser entendida também em relação à facilitação do acesso aos direitos de cidadania de modo geral. O fato de o agente comunitário de saúde visitar os moradores da comunidade em suas casas e ouvir relatos ou atuar sobre fatos que, muitas vezes, não são específicos à área da 
saúde estende seu papel de mediação a distintas esferas de organização da vida social.

A posição do ACS como mediador pode conter ambigüidades que resultam, por um lado, de sua convivência com a realidade e as práticas de saúde do bairro onde mora e trabalha e, por outro, de sua formação - que acontece, em geral, a partir de referenciais do modelo assistencial biomédico tradicional. Nunes et al. (2002) apontam a importância de explorar melhor a intermediação entre saberes realizada pelo ACS, alertando que esta pode ser entendida como uma tradução que vai do universo científico ao popular. Também David (2001) aborda a ambigüidade vivenciada pelo ACS e aponta que esta é geralmente entendida como negativa por ser contraditória, sendo que nesta ambigüidade pode residir a riqueza do processo de mediação na medida em que possibilita o reconhecimento das características dos diferentes pólos mediados.

Com relação ao sentido e direção da mediação, pode-se identificar um caráter vertical e assimétrico, já que o serviço prioriza suas orientações e procura convencer a população com relação ao valor do saber tecnocientífico. Trata-se de uma situação que apenas reproduz a lógica do controle sanitário dos serviços sobre a população. O caráter transformador da mediação se daria quando houvesse uma ruptura desta verticalidade, para que existisse maior compartilhamento do conhecimento e maior permeabilidade dos serviços quanto às necessidades e demandas da população.

Este artigo toma como base a tese de doutoramento $O$ agente comunitário de saúde na mediação de saberes, de autoria de Bornstein (2007), que teve como universo de pesquisa o Complexo da Maré, no município do Rio de Janeiro. O estudo pretendeu caracterizar o conflito entre as lógicas institucional e comunitária e as possibilidades de assunção pelos agentes comunitários de saúde das diferentes formas de mediação.

\section{Aspectos metodológicos}

Esta foi uma pesquisa qualitativa que utilizou a triangulação metodológica para a coleta de dados, obtidos por meio de entrevistas, consulta documental e observação participante.

O método de organização dos dados apoiou-se no enfoque de pesquisa qualitativa de Lefèvre e Lefèvre (2003), denominado “O discurso do sujeito coletivo (DSC)". Optou-se por não seguir a proposta metodológica completa do DSC, no entanto mantiveram-se as figuras metodológicas de 'expressões-chave' e 'idéias centrais'. A fim de expor a idéia dos entrevistados de forma sintética e organizada, foram construídas 'expressões-chave 
síntese' apresentadas sob a forma de depoimentos, buscando manter a característica individual do discurso.

A análise tomou como base a abordagem hermenêutica dialética (Minayo, 2002, p. 101), uma análise que “(...) busca apreender a prática social empírica dos indivíduos em sociedade em seu movimento contraditório", problematizando-se os achados à luz do referencial teórico adotado.

A coleta de dados empíricos foi realizada, sobretudo, no Posto de Saúde da Vila do João que é uma Unidade Básica de Saúde (UBS) vinculada à Secretaria Municipal da Saúde do Rio de Janeiro (SMS-RJ). Para a gestão desta unidade foi assinado um convênio entre a Unimar (União das Associações do Bairro Maré) e a SMS-RJ. No início da década de 1990 esta unidade havia sido fechada devido a incidentes de violência que ocorreram no local, sendo reativada em 1998 com uma equipe similar à do Pacs. Foram realizadas entrevistas semi-estruturadas entre outubro e dezembro de 2005, com nove ACS, duas enfermeiras e dois médicos. A observação participante foi facilitada pelo fato da pesquisadora ter trabalhado durante vários anos na Maré, o que possibilitou uma relação de confiança com as agentes comunitárias de saúde e com a população e, por outro lado, adquirir familiaridade com as questões investigadas. A observação foi não-estruturada e teve como objetivo captar as contradições, completar, exemplificar e verificar o material colhido por meio de entrevistas e documentos. Foram consultados documentos de fonte primária, referentes aos registros locais, e documentos de fontes secundárias, nas quais se inserem os registros realizados por instituições parceiras.

\section{A função educativa da mediação}

As diferentes formas de conduzir a mediação refletem diferentes concepções sobre o processo de produção do conhecimento e diferentes concepções políticas. Numa perspectiva que entende o conhecimento científico como objetivo e capaz de refletir a realidade de maneira mais fidedigna que o senso comum, a mediação educativa se processa de forma mais vertical, delegando-se ao profissional de saúde, sobretudo o de nível superior, o papel de 'representante' deste tipo de conhecimento.

Na perspectiva de uma educação crítica, o processo de produção do conhecimento tem como ponto de partida o conhecimento prévio e se desenvolve com base na sua problematização em contexto sociocultural específico. Nessa perspectiva, destaca-se a característica da construção compartilhada do conhecimento entre sujeitos com diferentes saberes que, no entanto, não são hierarquizados (Carvalho, Acioli e Stotz, 2001). Esta forma de entender o processo cognitivo tem uma implicação política, pois, como 
menciona Certeau, Girad e Mayol (1997, p. 339), “apropriar-se das informações, colocá-las em série, montá-las de acordo com o gosto de cada um é apoderar-se de um saber e com isso mudar de direção a força de imposição do totalmente feito e totalmente organizado."

De acordo com Luckesi (1990), existem três formas de entender o sentido da educação na sociedade, que podem ser expressas pelos seguintes conceitos: "educação como redenção; educação como reprodução; e educação como um meio de transformação da sociedade" [grifos nossos]. Para a educação redentora, a sociedade é entendida como "um conjunto de seres humanos que vivem e sobrevivem num todo orgânico e harmonioso, com desvios de grupos e indivíduos que ficam à margem desse todo" (Luckesi, 1990, p. 38). O papel da educação seria o de integrar harmonicamente os indivíduos no todo social já existente, corrigindo seus desvios.

De acordo com a segunda tendência, a educação faria parte da sociedade, sendo determinada por seus condicionantes econômicos, sociais e políticos. Seria necessário reproduzir os meios materiais e culturais da sociedade, e a força de trabalho é um de seus elementos, que possui uma vertente biológica e outra cultural. O papel da educação seria justamente o de viabilizar esta reprodução da força de trabalho do ponto de vista quantitativo (biológico) e qualitativo (cultural).

A terceira tendência entende a educação como "uma instância dialética que serve a um projeto, a um modelo, a um ideal de sociedade" (Luckesi, 1990, p. 49). A mediação realizada pela educação dependeria do tipo do projeto de sociedade. Dentre as possibilidades da terceira tendência, estaria a da educação transformadora a serviço de um projeto de libertação das maiorias dentro da sociedade.

A posição predominante entre os profissionais de saúde com relação ao trabalho educativo é a responsabilização do indivíduo pela mudança de padrões comportamentais que incidam sobre a situação de saúde. Buscam modificar o comportamento ou as condutas da população consideradas prejudiciais à saúde. Segundo Paulo Freire (1970), a corrente educativa onde existe uma transmissão de conhecimento de forma unilateral tem implícito o entendimento de que o educando não tem conhecimentos anteriores e, portanto, nele devem ser depositados os conhecimentos do educador. $\mathrm{O}$ autor refere-se a este tipo de educação como 'educação bancária', na qual o conhecimento é visto como "uma doação dos que se julgam sábios aos que julgam nada saber" (Freire, 1970, p. 67). Eymard Vasconcelos (2001, p. 123) denomina este tipo de educação de 'toca boiada', reportando-se à imposição de normas e comportamentos considerados adequados pelos técnicos, que conduzem a um caminho previamente determinado. Estabelece-se uma relação vertical e autoritária entre o profissional e a população, baseada na 
crença de que é o educador quem detém o saber e deve transmitir suas informações e ensinamentos.

De acordo com Valla (1996, p. 179), ao oferecer seu saber à população, o profissional estaria entendendo que o saber "da população é insuficiente e, por esta razão, inferior, quando na realidade, é apenas diferente". Considera que os 'profissionais/mediadores' têm dificuldade em admitir que também os grupos populares sejam produtores de conhecimento e, por esse motivo, assumem o papel de 'tutores' na relação com estes grupos. No campo da saúde, a imposição de normas e comportamentos se respalda no medo ao sofrimento, ao adoecimento, à morte. O que pode acontecer com quem não segue as prescrições é a principal argumentação desta concepção de educação.

A educação popular parte do princípio de que o educando possui um saber révio, adquirido em sua história de vida, sua prática social e cultural; este é o ponto de partida para a aquisição de novos conhecimentos. A relação que se estabelece entre educador e educando é necessariamente dialógica, baseada no reconhecimento da existência de diferentes saberes e na possibilidade de aprendizagem mútua.

Carlos Rodrigues Brandão (1981) se refere à existência de tipos de 'saber comunitário' que são passados de geração em geração, por meios comunitários de transferência: crenças e valores, formas de representação do mundo, lógicas e códigos próprios, formas próprias de saber: “assim, as formas próprias de educação do povo servem a ele como redes de resistência a uma plena invasão da educação e do saber 'de fora da classe'" (Brandão, 1981, p. 105).

Outro elemento fundamental na metodologia de educação popular é o entendimento da educação como um processo de busca e de invenção ou reinvenção que parte da ação e da reflexão do homem sobre o mundo para transformá-lo. A problematização das experiências ou situações vividas se constitui em desafio para a transformação e, portanto, em fonte para a organização do conteúdo programático do processo educativo: “a incerteza como caminho de ganhar a certeza" (Freire e Betto, 1991, p. 76). Freire aponta o motivo da falha de processos educativos baseados em conteúdos programáticos impostos, em que os assuntos são elaborados para o educando e não com ele, sem levar em conta o homem em situação; isto aumenta o risco de que se abordem temáticas que não fazem parte da experiência existencial do educando nem sejam do seu interesse.

De acordo com Carvalho, Acioli e Stotz (2001, p. 103), a construção do conhecimento por meio do compartilhamento de saberes consiste num diálogo: "todos os sujeitos são docentes de saberes diferentes". Este entendimento incorpora a visão de Santos (1989), na qual a caracterização do senso comum não tem como referência sua contraposição ao conhecimento cientí- 
fico. O senso comum ou o saber popular expressa a experiência da população, suas estratégias de vida; por outro lado, a ciência é fruto de estudos e experimentos realizados durante anos. Para Carvalho, Acioli e Stotz (2001), a relação entre o conhecimento científico e o senso comum, no que diz respeito à saúde, deve considerar: os limites do conhecimento científico sobre saúde no que se refere às causas das doenças e à sua cura; a importância da experiência da enfermidade e do conhecimento comum das pessoas; a concorrência entre diferentes sistemas médicos; a medicalização de comportamentos sociais e a complexidade do adoecer humano.

Boaventura Santos (1989, p. 41-42) entende que "caminhamos para uma nova relação entre a ciência e o senso comum, uma relação em que qualquer deles é feito do outro e ambos fazem algo novo" na intenção de construir "um senso comum esclarecido e uma ciência prudente".

A riqueza da atuação do agente comunitário de saúde na mediação de saberes se dá justamente por sua origem e inserção na comunidade onde atua e, ao mesmo tempo, por sua participação profissional no serviço de saúde; isto lhe possibilita o acesso ao saber popular e também ao tecnocientífico. A educação popular como metodologia e como movimento social aponta para uma mediação transformadora que, de acordo com a revisão bibliográfica realizada, não parece ser o enfoque principal encontrado nas experiências desenvolvidas na atualidade.

\section{A necessidade e as possibilidades da mediação}

De acordo com Gilberto Velho (2001), a existência da mediação fica mais nítida em uma sociedade não apenas altamente diferenciada como desigual, o que ocorre no meio metropolitano, em que os indivíduos "estão potencialmente expostos a experiências muito diferenciadas, na medida em que deslocam e têm contato com universos sociológicos, estilos de vida e modos de percepção da realidade distintos e mesmo contrastantes" (Velho, 2001, p. 20). Alguns indivíduos desempenhariam o papel de mediadores ao lidar com vários códigos e viver diferentes papéis sociais, fazendo o trânsito entre diferentes mundos, estilos de vida e experiências.

Na abordagem do tema mediação, Duarte (2001) aponta diferentes segmentos que fazem parte da sociedade moderna ocidental, tais como: erudito e popular, Zona Sul e Zona Norte, asfalto e morro, cidade e sertão, e sustenta que uma das metades é sempre hierarquicamente superior à outra. Comenta que a qualidade da mediação está relacionada à capilaridade existente entre os dois pólos da 'grande divisão'.

De uma maneira geral, no trabalho desenvolvido pelos agentes comunitários de saúde, os principais segmentos mediados são: a população 
residente na comunidade, em seus diferentes estratos, e os profissionais do sistema local de saúde. A mediação é realizada pelos agentes, em sua condição simultânea de moradores e profissionais de saúde.

No estudo realizado, procuraram-se identificar, nas práticas mediadoras dos ACS e nos seus discursos, características que evidenciem a forma de mediação realizada. Neste sentido, foi construída uma tipologia de mediação a partir das concepções de educação mencionadas anteriormente:

- Mediação convencedora, por meio da qual se busca transmitir ou repassar informação sobre atitudes e comportamentos considerados corretos, retificando os desvios existentes. Sua atuação se dá como algo 'externo' e seu papel é o de integrar os indivíduos no contexto já existente, viabilizando sua continuidade. A necessidade de uma continuidade harmônica da sociedade pode justificar uma educação vertical e autoritária. No caso da saúde, o medo da morte ou as conseqüências do não cumprimento da prescrição costumam ser as argumentações deste tipo de mediação.

- Mediação transformadora, na qual se enfatiza a transformação da sociedade numa perspectiva democrática. A educação é uma instância dialética que medeia esta transformação. Uma mediação deste tipo contribui para novas práticas em saúde, abertas ao reconhecimento da existência de diferentes saberes sobre a saúde, sejam eles médicos ou não médicos; considera os limites do conhecimento científico sobre saúde no que se refere às causas das doenças e à sua cura e reconhece a importância da experiência da enfermidade e do conhecimento comum das pessoas.

Com a elaboração desta tipologia se pretende principalmente caracterizar a oscilação entre dominação e transformação presente nos vários tipos de mediação realizados pelos agentes sem, no entanto, desconhecer a possibilidade de construção de outros tipos de mediação. A forma de mediação praticada não depende apenas da vontade ou qualidade dos ACS. Interferem múltiplos fatores entre os quais: as diretrizes dos serviços; as metas exigidas; a organização dos serviços e sua permeabilidade à demanda da população; a formação dos agentes de saúde e dos demais profissionais de saúde. No estudo realizado foram encontradas várias lógicas de mediações realizadas por uma mesma pessoa.

\section{A direção e as possibilidades de reorientação do modelo assistencial}

A Estratégia Saúde da Família tem sido apresentada como a possibilidade de substituição do modelo assistencial tradicional, orientado para a cura de doenças e hospitalocêntrico, por outro, cujas principais características são: o enfoque sobre a família a partir de seu ambiente físico e social; a adscrição de clientela por meio da definição de território de abrangência 
da equipe; a primazia das abordagens interdisciplinares e intersetoriais, em detrimento da ótica das especialidades médicas; a ação preventiva em saúde; a detecção de necessidades da população ao invés da ênfase na demanda espontânea. Desta forma, pretende incorporar os princípios básicos do SUS: universalização, descentralização, eqüidade, integralidade e participação comunitária.

Alguns autores, entre os quais Merhy e Franco (2002), questionam este 'discurso mudancista', apontando a normatividade da proposta do PSF; a mitificação do médico generalista; a falta de garantia na mudança do modelo 'médicocentrado'; e a lenta resposta das instituições de formação de profissionais com um novo perfil.

Albuquerque e Stotz (2004) consideram que, pelo fato de a atenção básica ser o principal locus para o desenvolvimento de ações de educação em saúde e sendo o PSF a principal estratégia de reorientação do modelo assistencial, este pode ser considerado um ambiente favorável ao desenvolvimento da educação popular em saúde. No entanto, apesar do ambiente favorável criado pelo Pacs/PSF para ações baseadas na integralidade da atenção e no princípio dialógico do conhecimento entre saberes diferentes, estas potencialidades não garantem a substituição do modelo tradicional, vertical e orientado para as doenças. É necessária uma nova postura dos profissionais, maior participação da comunidade e maior permeabilidade dos serviços às necessidades e demandas da população. Na medida em que grande parte dos profissionais de saúde considere seu conhecimento como 'o correto', a tendência é que o ACS faça o mesmo e procure realizar a mediação do convencimento. Na cadeia de transmissão do conhecimento, o ACS passa a ser aquele que facilita essa transmissão da equipe para a população, numa lógica da simples multiplicação do conhecimento.

A metodologia de educação popular é entendida neste artigo como base para uma mediação transformadora e como alternativa de abordagem dos problemas de saúde, necessária para a reorganização dos serviços de saúde.

\section{O que é mediado}

Na pesquisa, foi constatado que a mediação era feita em relação às diferentes situações descritas a seguir.

Com relação à mediação das informações sobre condições de vida, na observação participante realizada, foi confirmado o conhecimento que os agentes de saúde têm em relação às condições e situações de vida das famílias. Durante o caminho percorrido na comunidade, as agentes foram paradas várias vezes e as conversas indicavam conhecimento anterior dos casos. Esta também foi a situação durante as visitas domiciliares. No 
entanto, algumas ACS afirmaram que os médicos nem sempre usavam a informação disponibilizada por elas como referência para seus atendimentos.

Um dos médicos apontou uma das razões para a limitação na troca de conhecimentos com os ACS:

A gente fica confinado naquele consultório e a nossa relação com os outros profissionais é uma relação bastante limitada (Médico 2).

Ainda assim, a valorização do conhecimento do agente comunitário de saúde sobre o contexto e a situação de vida das famílias foi mencionada pelo mesmo médico como uma contribuição ao seu atendimento.

Nas entrevistas, de maneira geral, os agentes comunitários de saúde consideraram que sua atenção às situações de risco na comunidade era permanente:

Meu papel é estar de olho todos os dias, enquanto profissional de saúde. É uma sentinela, vamos dizer assim (ACS5).

Ao mencionarem aspectos das condições de vida da população relacionados aos problemas de saúde, as ACS demonstraram ter uma concepção de risco que inclui fatores não específicos da saúde que fazem parte do conceito ampliado de saúde.

O risco era entendido pelas agentes comunitárias de saúde como critério na priorização de visitas, ainda que existisse a consciência da necessidade de visitar domicílios que pareciam não apresentar nenhum problema. A importância destas visitas se justificava pelo fato de que nem todos os riscos podiam ser detectados à primeira vista, como era o caso das doenças sexualmente transmissíveis, da violência doméstica e a 'baixa auto-estima'.

Algumas das situações monitoradas e apoiadas pelos agentes comunitários de saúde foram: violência doméstica; problemas de desenvolvimento infantil; mediação entre idosos e familiares; e a busca de recursos para a sobrevivência de moradores, além dos problemas específicos da saúde como casos de hanseníase, tuberculose e gestante sem acompanhamento pré-natal.

A ampla observação realizada pelos ACS durante a visita domiciliar foi, ao mesmo tempo, questionada por uma das enfermeiras como uma possível interferência do Estado na vida da população, uma vez que existe um controle sanitário sobre a família. Por outro lado, foi possível observar nas visitas domiciliares a satisfação da maioria dos moradores em receber as ACS.

Passamos agora a examinar a mediação do acesso dos moradores aos serviços. Segundo Tomaz (2002), existe uma 'super-heroização' do agente comunitário de saúde, já que as expectativas institucionais atribuem a este 
profissional o papel de ser a 'mola propulsora da consolidação do SUS'. No entanto, do depoimento das ACS depreende-se que as expectativas da população também são enormes. Uma das entrevistadas mencionou, em tom de brincadeira, que os moradores pensavam que ela fosse a 'salvadora da pátria'. A principal expectativa dos moradores era a facilitação do acesso ao serviço de saúde.

Orientação no primeiro momento, não é isso que eles procuram, não. Eles querem o número para atendimento médico (ACS 5).

Esta expectativa ia além do sistema local de saúde, incluindo as referências para serviços de maior complexidade, o que muitas vezes provocava na agente um sentimento de fracasso, quando não lograva realizar esta mediação.

Para o morador, o agente comunitário de saúde representava ainda a possibilidade de um primeiro atendimento imediato, já que o acesso aos demais profissionais podia demandar um período de tempo maior.

As dificuldades de acesso dos moradores aos serviços de saúde geravam reclamações aos ACS, que eram enfrentadas de diferentes formas pelos agentes:

Quando eu não consigo ajudar, eu falo: "Infelizmente não deu por causa disso, disso. Não tive condições". E o morador diz: “Tudo bem, eu vi o teu esforço, tua boa vontade, né?" (ACS 8).

Se eu chegar lá e não levar a resposta, nossa, naquela casa eu nem vou mais (ACS 9).

Uma das agentes comunitárias de saúde preferia falar diretamente com o morador sobre as dificuldades encontradas e dizia ser entendida por eles, enquanto a outra ficava temerosa da reação do morador e procurava se desculpar pelo insucesso na mediação, assumindo de certa forma a responsabilidade da instituição.

No que se refere à mediação do funcionamento do serviço local, a visita domiciliar era a principal atividade realizada pelos agentes comunitários de saúde, mesmo que o modelo implantado na unidade de saúde estudada demonstrasse valorizar outras atividades educativas de cunho coletivo.

Verificou-se que o grande número de famílias sob a responsabilidade de um só agente comunitário de saúde dificultava seu acompanhamento, uma vez que não se tinha mantido o número de famílias por agente determinado nas normas do Pacs. Este número foi sempre superior, de início devido ao pequeno número de agentes comunitários de saúde, e depois por causa do desvio de vários agentes das suas funções. Em virtude de a equipe e a 
própria unidade estarem situadas dentro da comunidade, sentiam ser impossível excluir um grupo do atendimento. A realização de tarefas fora de suas funções, como a de auxiliar de enfermagem e as atividades administrativas, provocava sentimentos contraditórios, já que algumas ACS gostavam de realizá-las e sentiam que estas atividades proporcionavam um aprendizado, outras se sentiam fora de função.

Ainda que o cadastro feito pelas ACS abordasse a situação da família como um todo, esta informação não era utilizada pelos médicos que continuavam fazendo consultas individuais.

Entre as mediações realizadas pelos agentes, foram mencionadas: a identificação de riscos para a saúde na comunidade, a facilitação tanto da adesão do morador ao tratamento como da comunicação entre os profissionais de nível superior e os moradores e a disponibilização de informações sobre o funcionamento do serviço.

De maneira geral, as agentes comunitárias de saúde entrevistadas afirmaram que os moradores as abordavam em vários lugares da comunidade e em qualquer horário. Esta abordagem provocava sentimentos contraditórios: prazer pelo reconhecimento da população -

Eu acho muito legal e gratificante quando as crianças dizem: ‘Ih, lá vai a tia do Posto' (ACS 4)

- e desgaste pela sobrecarga de trabalho.

Uma atribuição exercida pelos agentes comunitários de saúde era a de ouvidor do próprio serviço de saúde o que lhe possibilitava contribuir na avaliação do trabalho, desde que existisse um espaço para a exteriorização de suas observações. Durante a observação participante, foram acompanhados dois casos em que os moradores fizeram queixas sobre o Posto de Saúde para as ACS:

Os clientes se queixam quando são mal atendidos e o agente comunitário de saúde fica com cara de tacho (Enfermeira 1).

Na experiência estudada, no que diz respeito à mediação presente nas ações educativas, foi observado que o processo de trabalho procurou se nortear pelos princípios da educação popular, ao reconhecer a importância da história da população e buscar a participação de todos na elaboração e no desenvolvimento do projeto da própria UBS. Os trabalhos educativos realizados em creches, escolas e nos logradouros da comunidade foram uma constante nos primeiros anos. Também se levaram para as praças procedimentos de rotina efetuados dentro da unidade, com o intuito de se estabe- 
lecer uma aproximação e intercâmbio com a população. O tema educação popular foi discutido em algumas oportunidades com a equipe, levando-a ao entendimento de que cada contato com a população poderia ser uma oportunidade educativa. Neste sentido, a recepção na portaria da unidade, a busca de faltosos no domicílio, as avaliações periódicas e as consultas coletivas eram consideradas atividades educativas.

A inserção dos médicos neste processo foi mais restrita, em parte devido à falta de disponibilidade da maioria dos profissionais, que se limitava a cumprir o atendimento ao número de consultas estipulado. Por outro lado, existia uma cobrança da própria população e dos demais profissionais de saúde, que esperavam do médico o atendimento aos doentes. Esta situação se devia, em parte, à discrepância entre a demanda e a oferta de consultas e também correspondia ao modelo tradicional de atenção, predominante na prática dos profissionais de saúde.

Houve consenso entre os entrevistados quanto ao reconhecimento da dificuldade, sobretudo dos médicos, em se comunicar com a população, o que justificaria a necessidade de uma 'tradução' feita pelo agente comunitário de saúde. Foram citados exemplos em que o morador pedia ao ACS explicações dadas antes pelos médicos, mas que não haviam sido entendidas.

Uma das agentes interpretou esta atitude dos médicos como uma falta de reconhecimento da capacidade da população em entender seu conhecimento, o que corresponderia a uma concepção de educação.

\footnotetext{
“Tem ' $\mathrm{n}$ ' vezes que a gente chega no consultório, o cara fala um monte de coisas que a gente não entende, sai de lá não entendendo nada do que você tem. E eu acho que por trás disso também tem um discurso, né? Tá implícito aí que o cara tá dizendo que você não entende nada, por isso ele não te falou de um outro jeito" (ACS 5).
}

Nesta expressão podem ser identificadas características da concepção chamada por Paulo Freire (1970, p. 67) de 'educação bancária', em que a transmissão de conhecimentos é feita de forma unilateral, partindo do saber técnico, hierarquicamente superior, sem levar em conta o saber popular.

As ações coletivas e educativas são mencionadas nos documentos oficiais como fazendo parte das atribuições dos ACS, mas na realidade não existia uma cobrança oficial sobre este tipo de trabalho, já que a ênfase da avaliação se voltava para a produtividade baseada em ações individuais e para os indicadores de saúde registrados no Sistema de Informação da Atenção Básica (Siab). De parte dos agentes comunitários de saúde existe o reconhecimento de que estas atividades fazem parte de suas atribuições. 
Um dos fatores que dificultava o desenvolvimento de atividades educativas era a sobrecarga de trabalho do ACS, com tarefas burocráticas que faziam parte das suas atribuições, e o desvio de função.

Olha, infelizmente o nosso trabalho agora tá muito burocrático, muito. Antigamente a gente tinha que se preocupar mais assim com a família. Hoje em dia a gente tem que dividir: preocupar com a família e se preocupar também com a burocracia. Uma família que você visita tem que anotar em três lugares diferentes. (ACS 8)

Na verdade o agente comunitário é pra tudo. Se, por exemplo, o médico falta, a agente é que tem que ir na casa de todos os cliente para remarcar as consultas. Como é que o ACS vai fazer trabalho com os grupos da comunidade? (E 1).

Quanto à mediação de situações que extrapolam a temática específica da saúde, Nogueira, Silva e Ramos (2000) apontam a facilitação do acesso aos direitos de cidadania de modo geral como uma das vertentes da mediação. As informações encontradas neste estudo revelaram que o conteúdo da mediação se define de acordo não só com as orientações fornecidas pela instituição, mas também com a realidade encontrada pela agente comunitário de saúde durante o desenvolvimento de seu trabalho.

O agente comunitário de saúde tem que ter uma abrangência maior de conhecimento, inclusive porque ele lida com todos os problemas das famílias, seja problema de saúde, seja problema de falta de recursos na educação, relações familiares, e eles têm que, de alguma maneira, participar disso (E 1).

A escolha dos assuntos a serem abordados na visita domiciliar dependia também da prioridade estabelecida pelo agente. Por exemplo, a ACS 8 procurava falar sobre estratégias de enfrentamento das dificuldades da vida:

Eu procuro sempre falar sobre a importância da auto-estima. Que a pessoa sempre se esforce para passar pelas barreiras. Às vezes as pessoas falam assim: "Ah porque na minha família todo mundo é pobrezinho, ninguém tem estudo, não tem nada." Mas se chegou até você, você tem que mudar essa situação (ACS 8).

Foram relatados casos de mediação de problemas dentro da própria família, como o da adolescente grávida que não conseguia contar sua situação para a mãe, os casos de abandono de idosos e também aqueles em que as agentes comunitárias de saúde tiveram que acompanhar o morador em exames ou consultas devido à ausência de algum familiar. 
O apoio emocional e psicológico foi, sem dúvida, também um importante foco do trabalho do agente comunitário de saúde no estudo realizado. Vários foram os depoimentos neste sentido:

Às vezes esperam conversar, desabafar, isso acontece muito. "Ah, dona Fulana, poxa, senta aqui que eu quero conversar um pouco com a senhora!" Então às vezes eu deixo, eu faço só uma visita, entendeu? Aí às vezes ali ela chora... eu deixo ela desabafar. Aí ela mesma fala: "eu tou mais leve." (ACS 6).

Na discussão sobre o perfil do ACS, Nogueira, Silva e Ramos (2000) fazem referência ao seu papel como um trabalhador genérico, que não tem similar entre as profissões de saúde tradicionais, caracterizando-o como um trabalhador sui generis. No entanto, mesmo abordando temas variados, que fazem parte da própria situação de vida com a qual o ACS se depara, seu foco principal é a saúde, sobretudo se considerarmos que os fatores que incidem sobre o processo saúde-doença são multicausais. Reforçaram ainda seu papel como trabalhador de saúde, por um lado, as expectativas da população, que reconhece no ACS um mediador do acesso a este serviço, e por outro, a própria orientação e a cobrança feitas pelas instituições de saúde sobre seu trabalho.

\section{A forma de mediação presente no processo de trabalho dos ACS}

Este foi o eixo central da pesquisa e entre as ACS entrevistadas várias foram as formas encontradas de realizar a mediação. Este fato pode ser relacionado às diversas formas de reconhecer o conhecimento popular.

Em vários casos houve contradições no discurso de uma mesma pessoa, como, por exemplo, no da agente comunitária de saúde que falou de troca de conhecimentos, mas ao citar o conhecimento do morador parecia não valorizá-lo como positivo. Na sua prática, indicava haver uma transmissão de conhecimento, o que corresponde a uma concepção vertical da educação:

A gente como profissional vai lá na casa do morador pra poder escutar, pra ajudar, ensinar como estar prevenindo a doença. A gente não vai lá pra ensinar tudo. A gente leva um pouco do que a gente sabe, mas a gente aprende muito também (ACS 2).

Ao mencionar o conhecimento existente entre os moradores, disse:

Na minha área lá é assim: sentiu uma dor de cabeça, toma logo dipirona; sentiu dor de barriga, ou faz um chazinho de broto de goiaba ou fala logo que é verme. 
Lá eles gostam muito de tomar remédio do jeito que eles acham. Aí o vizinho fala, "ah eu tomei esse remédio, toma você também". (ACS 2).

A conquista da confiança do morador favoreceu, neste caso, a construção de um espaço para 'chamar a atenção':

Porque eu não vou chegar assim na casa e falar: “Ó, varre a sua casa, que está suja!" No outro dia a mulher não deixa eu nem passar da porta. Mas quando a gente vai pegando intimidade, aí a gente já é praticamente parte da casa. Chego lá ela quer me dar café, aí eu já posso falar. Já sei que se eu disser assim: “Olha, essa criança está descalça, bota chinelo nela. Ó, vai lavar a mão, tua unha está suja, não põe na boca", aí a mãe já não esquenta 'd'eu' estar falando (ACS 2).

No entanto, reconheceu que às vezes não adiantava falar, porque se o morador não acreditava nestes conhecimentos, ela não conseguia convencer.

Eles podem às vezes assim fingir que vai fazer. Mas eles prestam bastante atenção, aceitam tranqüilos numa boa. Agora quando eu saio de lá, se eles vão fazer o que eu falei, aí não dá pra saber (ACS 2).

A educação como transmissão de saberes fica clara no discurso de outra ACS, que expressa:

Eu me considero um profissional de saúde à medida que eu passo as informações que me são passadas, pra orientar as pessoas, para melhorar a saúde, informar o que elas precisam fazer, o como fazer, aonde se dirigir (ACS 1).

Sobre o conhecimento da população, opinou:

Conhecimento de fato, eu acho que não tem. Tem muita gente curiosa e tem gente que se mete a médico. Tá com isso toma isso; ele passou pra mim, toma pra você também. A gente escuta muito isso aqui. Aí a gente aconselha: "não, não pode, o remédio que serve pra você não serve pra ele, você tem um organismo, ele tem outro" (ACS 1).

Ao mesmo tempo, quando perguntada se achava que tinha aprendido alguma coisa com a população, esta agente comunitária de saúde afirmou que aprendera no dia-a-dia, com a experiência de vida que a população 'passou' para ela. Disse que seu filho ficara bom 'rapidinho' da crise de bronquite com o uso de plantas medicinais indicadas por uma moradora.

Por meio da análise das fichas de acompanhamento preenchidas pelas ACS, também foi possível detectar algumas características da mediação rea- 
lizada. Por exemplo, no caso de Gilson, que estava com hanseníase, foi possível observar que o morador teve a liberdade com a ACS para manifestar sua vontade de abandonar o tratamento. Esta abertura do morador possibilitou à ACS argumentar, fundamentada no conhecimento tecnocientífico, para que ele não abandonasse o tratamento. Outras características mencionadas em várias fichas foram: o cuidado na abordagem de problemas graves, no sentido de não alarmar a família; a persistência no acompanhamento, o que supõe uma responsabilidade com o resultado de seu trabalho e o processo de conquista da confiança dos moradores.

Segundo as agentes comunitárias de saúde, as 'estratégias' adotadas na mediação são aprendidas na sua própria experiência de trabalho. Algumas das 'estratégias' mencionadas são: o diálogo; a importância de ouvir e mostrar interesse pelo problema do morador; entender a ação educativa como um processo cujos resultados nem sempre são percebidos de imediato; compreender a situação do outro e saber aguardar o momento adequado para desenvolver seu trabalho. Estas 'estratégias' podem ser utilizadas para as várias maneiras de realizar a mediação, mas de qualquer forma significam o reconhecimento de que não pode haver uma imposição.

Na experiência estudada foi possível perceber que mesmo os profissionais que vêm de fora da área são levados a entender que a imposição de regras encontra maiores obstáculos em unidades situadas dentro da comunidade. É como se o fato de estar no terreno do outro exigisse o respeito à sua cultura e às suas regras. $O$ 'respeito' pode ser fruto de um real interesse ou de uma abertura para o conhecimento do outro, mas pode também ser fruto do medo à violência, ou ainda ser fruto de uma situação profissional, em que o empregador faz parte da comunidade local. Mesmo assim, existem variações, uma vez que a imposição de regras é menos viável nas visitas domiciliares, nas quais o profissional se desloca para o espaço do morador, e mais viável no consultório, onde, a portas fechadas, o poder do profissional é maior.

Um discurso mais próximo a uma mediação transformadora foi encontrado no depoimento de uma ACS que, além de reconhecer que todos têm um saber, afirmou partir dele para sua ampliação.

Ah, nenhuma pessoa, nenhum morador não é totalmente indouto. Todo mundo tem um certo conhecimento. Uns têm pouco, outros têm menos ainda, outros têm mais, mas sempre alguém tem um certo conhecimento. E dentro daquele conhecimento que ele tem, aí a gente vai apenas abrindo o leque, apenas abrangendo. Vai trabalhando com eles próprios (ACS 8). 
Esta mesma agente comunitária de saúde afirmou orientar seu trabalho a partir das necessidades detectadas no diálogo com o morador e exemplificou a lógica problematizadora no processo educativo:

Eu aprendi que o agente tem que muitas das vezes ouvir mais do que falar, às vezes a pessoa tá precisando de uma palavra de ânimo, até mesmo fora da saúde. (ACS 8)

Quando vejo a criança com corrimento no nariz, pergunto: "Ele está resfriado, tá com alergia?" E a mãe diz: "Ah, tem um tempão que ele está assim." Aí vejo as condições da casa e, com cuidado, pergunto: "De repente pode ser muita poeira, né?" Aí a mãe diz: "Ah é, aqui tem muita poeira." Aí a gente sempre dá uma orientação (ACS 8).

Mesmo havendo práticas diferentes de mediação, na observação realizada foi possível notar a satisfação dos moradores em receber os ACS. Todos os entrevistados expressaram esta mesma percepção e uma das ACS que fora contratada mais recentemente manifestou sua surpresa diante da boa receptividade da população:

Tem casa que eu chego, aí a pessoa já vai abrindo a porta, já manda entrar, conversa, antes 'd'eu' perguntar, a pessoa já tá falando. Teve caso da primeira visita minha, quando eu bati na porta a pessoa já começou a falar, porque já conhecia o trabalho do agente (ACS 7).

O material de estudo permitiu conhecer um contexto desafiador, marcado pela violência, pela pobreza e a falta de oportunidades para seus moradores, que exigia solidariedade, espírito de luta e criatividade para enfrentar as adversidades. Nem todos têm as mesmas condições para este enfrentamento; alguns são capturados pelo ciclo de problemas, no qual o desemprego, a grande quantidade de filhos, o baixo nível escolar dificultam a superação da pobreza e das próprias condições para enfrentar a vida. Estes moradores precisam, sobretudo, de uma voz de alento; esta foi também a percepção dos agentes de saúde, que ao mesmo tempo em que priorizavam em suas visitas aqueles moradores que se encontravam entre os critérios de monitoramento do Pacs, dedicavam parte do seu tempo àqueles que precisavam mais de seu apoio, e eram os que se encontram em situação de maior vulnerabilidade.

O contexto desafiador, ao mesmo tempo em que provoca repulsa ou temor naqueles que se recusam a entrar, atrai e fascina os profissionais que procuram entendê-lo, aproveitando esta grande oportunidade de aprender e exercer a criatividade. 


\section{Considerações finais}

A importância de identificar a forma de mediação presente no trabalho dos agentes comunitários de saúde se deve, por um lado, à importância da Estratégia Saúde da Família na política de saúde brasileira; por outro, à identificação de uma potencialidade nos ACS para assumirem a posição de educadores populares. Em agosto de 2008 existiam 225.754 agentes comunitários de saúde, atuando em 5.337 municípios brasileiros (Brasil, 2008); na medida em que sua mediação seja transformadora, fortalece-se a construção de um sistema de saúde humanizado e a luta por uma sociedade mais justa.

Como afirmado anteriormente, os principais segmentos mediados pelos agentes comunitários de saúde neste estudo foram: a população residente na Maré, em seus diferentes estratos, e os profissionais que conformam o sistema local de saúde. O conteúdo desta mediação abarcou principalmente os conhecimentos sobre situação de saúde e condições de vida da população que eram disponibilizadas aos demais profissionais; o conhecimento biomédico disponibilizado à população; a viabilização do acesso dos moradores aos serviços de saúde; a facilitação do funcionamento do serviço local de saúde; e a promoção da cidadanização viabilizando o acesso da população a outros serviços e informações.

A forma como cada um exerce sua função mediadora é muitas vezes contraditória e depende em parte de opções individuais e em parte das cobranças institucionais. Devido a sua origem e experiência de vida, o agente se encontra imerso no conhecimento popular e, por sua formação e experiência profissional, incorpora o conhecimento científico.

Ao mesmo tempo em que:

- Existe a identificação e um sentimento de pertencimento dos ACS em relação à comunidade, o que ficou claro nas entrevistas e se fundamenta nas suas experiências de vida no mesmo contexto do restante da população;

- Os moradores têm confiança e reconhecem o papel do ACS;

- Os moradores cobram do ACS a resolução de seus problemas;

- Existe um compromisso da maioria dos ACS com o resultado do seu trabalho, o que pôde ser constatado pela persistência com que os casos foram acompanhados, inclusive fora do seu horário de trabalho.

Por outro lado:

- As ACS entrevistadas não se incluíam no estrato mais pobre da população da Maré, pelo fato de terem carteira assinada e seus direitos laborais garantidos;

- O salário do agente comunitário de saúde era o mais baixo da área técnica da equipe, quase a metade do salário do auxiliar de enfermagem;

- As ACS recebiam uma formação permanente que destacava o conhecimento tecnocientífico. 
- As ACS faziam parte também do sistema local de saúde, que é um dos pólos mediados e cujo poder se impõe sobre seu trabalho.

As formas de mediação praticadas pelos ACS resultaram, em grande parte, desta ambigüidade, pois faziam parte dos dois principais segmentos mediados. O ACS, cujo principal procedimento de trabalho é a visita domiciliar, nutre o pólo correspondente ao sistema local de saúde com as informações sobre condições de vida, formas de comunicação, comportamentos e até sobre a situação de violência. É considerado pelos outros profissionais como um elemento fundamental na equipe. No entanto, apesar de ser reconhecido como mediador pelos dois segmentos, este fato não determina a forma de mediação, que depende em grande parte da "capilaridade entre os dois pólos da grande divisão" (Duarte, 2001).

O risco de que o agente comunitário de saúde assuma uma mediação convencedora é grande, quando o pólo da população não possui instâncias organizativas que possibilitem a cobrança da permeabilidade do serviço às suas necessidades e demandas e que a equipe de saúde assuma uma tendência normatizadora e tecnicista. O conhecimento que o agente comunitário de saúde tem sobre a experiência e a linguagem da população pode ser utilizado de forma vertical para passar informações, viabilizar a continuidade de tratamentos e atingir as metas do serviço. Um exemplo de mediação convencedora foi o caso de Rosa e Roberta, mães adolescentes de 13 e 15 anos, acompanhadas por uma agente comunitária de saúde que, durante algum tempo, tentou convencê-las sobre a importância de se inscreverem no planejamento familiar do posto de saúde. Na quarta visita, a ACS descobriu que as meninas não haviam feito a inscrição por não saberem o que significava planejamento familiar.

As cobranças institucionais feitas ao agente comunitário de saúde encontram seu suporte no Siab, que é o principal instrumento de monitoramento e avaliação das ações do Pacs e do PSF. Estas cobranças privilegiam a forma de mediação convencedora, na medida em que pretendem convencer a população a seguir comportamentos e atitudes considerados corretos. O ACS, depois de 'ganhar a confiança' do morador, se sente autorizado a 'cobrar' ou mesmo 'chamar a atenção' daqueles que não seguem este padrão, seja com relação ao planejamento familiar, ao uso da camisinha, ou à prescrição de um tratamento. A vulnerabilidade do usuário pode justificar a necessidade de convencimento, em que a obrigação de seguir determinados comportamentos é justificada pelo medo, como por exemplo, o medo da morte.

A função mediadora dos ACS pode ser de grande importância na mudança do modelo assistencial, mas cabe perguntar se a Estratégia de Saúde da Família contém os elementos que permitem o desenvolvimento do potencial transformador dos agentes. 
Ao abordar a reorientação de modelo assistencial almejada por meio da implantação da Estratégia de Saúde da Família, as principais características mencionadas são: o enfoque sobre a família, a adscrição de clientela, a estruturação da equipe multiprofissional, a ação preventiva em saúde, a detecção de necessidades da população ao invés da ênfase na demanda espontânea. Estas são características organizativas, que não influem necessariamente numa mudança de modelo que contemple a eqüidade, a integralidade, a humanização e a participação popular. A tendência ao controle sanitário, à burocratização das atividades e à focalização da atenção básica nos segmentos mais pauperizados da população dificulta ou até mesmo impede o fortalecimento do vínculo com a população. Pela proximidade do ACS com os demais moradores, a relação acaba se tornando, em parte, uma relação pessoal, visto que o compromisso com as necessidades e demandas locais nem sempre é assumido institucionalmente. Por outro lado, dado o papel e as atribuições dos agentes de saúde, existe uma pressão no sentido da institucionalização da mediação.

Nesse contexto, a coexistência das formas de mediação convencedora e transformadora favorece a adoção da educação popular (Freire, 1995; Valla, 1996; Stotz, 1993; Vasconcelos, 2001) enquanto metodologia cujos princípios (fortalecimento da autonomia, participação popular, trabalho coletivo, reflexão crítica sobre a realidade) fortalecem a mediação transformadora na mudança do modelo assistencial.

Este estudo possibilitou o conhecimento das práticas dos ACS que nem sempre são visíveis institucionalmente. Neste sentido, permitiu apontar sugestões, tanto no que se refere ao reforço da mediação transformadora como na permeação dos serviços às necessidades e demandas da população.

Quanto ao fortalecimento da mediação transformadora:

- Considerar a educação popular como eixo estruturante, em torno do qual se dê não só a formação dos agentes, mas todo o trabalho daquela estratégia que é responsabilizada pela mudança do modelo de atenção básica. Para ser coerente com seus princípios, a educação popular não pode ser um tema entre tantos outros na formação dos agentes.

- Flexibilizar a formação dos ACS com a incorporação de temáticas locais.

- Desburocratizar do trabalho dos ACS e de toda a equipe de saúde e o controle sobre o desvio de função, abrindo espaço para o trabalho educativo.

Em relação à permeação dos serviços às necessidades e demandas da população:

- Avaliar permanentemente os serviços de forma conjunta: gestor, equipe de profissionais de saúde e usuários.

- Criar espaços de troca de experiências e informações entre os funcionários das unidades de saúde. 
- Criar uma instância de participação da população em conjunto com gestores e trabalhadores da saúde.

Estas são questões fundamentais para que o modelo assistencial possa corresponder às necessidades e expectativas da população e se aproximar dos princípios de integralidade, eqüidade, humanização e participação popular.

\section{Notas}

1 Pesquisadora visitante do Laboratório de Educação Profissional em Atenção em Saúde da Escola Politécnica de Saúde Joaquim Venâncio, da Fundação Oswaldo Cruz (EPSJV/Fiocruz), Rio de Janeiro, Brasil. Doutora em Saúde Pública pela Escola Nacional de Saúde Pública Sergio Arouca, da Fundação Oswaldo Cruz (Ensp/ Fiocruz).<vejoana@fiocruz.br $>$

Correspondência: Fundação Oswaldo Cruz, Escola Politécnica de Saúde Joaquim Venâncio, Avenida Brasil, 4.365, Manguinhos, Rio de Janeiro, Brasil, CEP 21040-360.

2 Pesquisador titular da Escola Nacional de Saúde Pública Sergio Arouca, da Fundação Oswaldo Cruz (Ensp/Fiocruz). Doutor em Saúde Pública pela Escola Nacional de Saúde Pública Sergio Arouca, da Fundação Oswaldo Cruz. <stotz@ensp.fiocruz.br>

\section{Referências}

ALBUQUERQUe, Paulette Cavalcanti de; STOTZ, Eduardo Navarro. A educação popular na atenção básica à saúde no município: em busca da integralidade. Interface Comunicação, Saúde, Educação, v. 8, n. 15, p. 258-74. 2004.

BORNSTEIN, Vera Joana. O agente comunitário de saúde na mediação de saberes. 2007. Tese (Doutorado em Saúde Pública). Escola Nacional de Saúde Pública Sergio Arouca, Fundação Oswaldo Cruz, Rio de Janeiro, 2007.

BORNSTEIN, Vera Joana; STOTZ, Eduardo Navarro. Concepções que integram a for- mação e o processo de trabalho dos agentes comunitários de saúde: uma revisão da literatura. Ciência \& Saúde Coletiva; v. 13, n. 1, p. 259-268. 2008.

BRANDÃO, Carlos Rodrigues. O que é educação. 1. ed. São Paulo: Brasiliense, 1981.

BRASIL. Ministério da Saúde. Departamento de Atenção Básica. 2008. Disponível em: $<$ http://dtr2004.saude.gov.br/dab/abnumer os.php>. Acesso em: 25 out. 2008.

CARVALHO, Maria Alice Pessanha; ACIOLI, Sonia; STOTZ, Eduardo Navarro. O processo de construção compartilhada do conhe- 
cimento: uma experiência de investigação científica do ponto de vista popular. In: VASCONCELOS, Eymard M. (Org.). A saúde nas palavras e nos gestos: reflexões da rede de educação popular e saúde. São Paulo: Hucitec, p. 101-114, 2001.

CERTEAU, Michel de; GIRAD, Luce; MAYOL, Pierre. A invenção do cotidiano-2: morar, cozinhar. Petrópolis: Vozes, 1997.

DAVID, Helena Maria S. Leal. Sentir saúde: a religiosidade como categoria metodológica no trabalho de educação em saúde junto às classes populares. 2001. Tese (Doutorado em Saúde Pública). Escola Nacional de Saúde Pública Sergio Arouca, Fundação Oswaldo Cruz, Rio de Janeiro, 2001.

DUARTE, Luiz Fernando. Comentários. In: VELHO, Gilberto; KUSCHNIR, Karina (Orgs.). Mediação, cultura e politica. Rio de Janeiro: Aeroplano Editora, p. 129-136, 2001.

FREIRE, Paulo. Pedagogia do oprimido. 3. ed. Rio de Janeiro: Paz e Terra, 1970.

Política e educação. São Paulo: Cortez, 1995.

FREIRE, Paulo; BETTO Frei. Essa escola chamada vida: depoimentos ao repórter Ricardo Kotscho. 7. ed. São Paulo: Ática, 1991.

LEFÈVRE, Fernando; LEFÈVRE, Ana Maria Cavalcanti. O discurso do sujeito coletivo: um novo enfoque em pesquisa qualitativa. Caxias do Sul: Educs, 2003.

LUCKESI, Cipriano Carlos. Educação e sociedade: redenção, reprodução e transformação. In: Filosofia da educação. São Paulo: Cortez, p. 37-52, 1990.

MERHY, Emerson Elias; FRANCO, Túlio Batista. Programa Saúde da Família: somos contra ou a favor?. Saúde em Debate, v. 26, n. 60, p. 118-122, 2002.

MINAYO, Maria Cecília de Sousa. Hermenêutica-dialética como caminho do pen- samento social. In: MINAYO, Maria Cecília de Sousa; DESLANDES, Suely Ferreira (Orgs.). Caminhos do pensamento: epistemologia e método. Rio de Janeiro: Editora Fiocruz, p. 83-107, 2002.

NOGUEIRA, Roberto Passos; SILVA, Frederico Barbosa; RAMOS, Zuleide do Valle Oliveira. A vinculação institucional de um trabalhador sui generis: o agente comunitário de saúde. 2000. Textos para discussão, Ipea, n. 735. Disponível em: $<$ www.ipea.gov.br.>. Acesso em: 27 abr. 2008.

NUNES, Mônica de Oliveira et al. O agente comunitário de saúde: construção da identidade desse personagem híbrido e polifônico. Cadernos de Saúde Pública, v. 18, n. 6, p. 1.639-1.646, 2002.

SANTOS, Boaventura de Sousa. Ciência e senso comum. In: SANTOS, Boaventura de Sousa. Introdução a uma ciência pós-moderna. Rio de Janeiro: Graal, p. 31-45, 1989.

STOTZ, Eduardo Navarro. Enfoques sobre educação e saúde. In: VALLA, Victor Vincent. Participação popular, educação e saúde: teoria e prática (Org.). Rio de Janeiro: Relume Dumará, p. 12-22, 1993.

TOMAZ, João Batista Cisne. O agente comunitário de saúde não deve ser um 'superherói'. Interface - Comunicação, Saúde, Educação, v. 6, n. 10, p. 84-87, 2002.

VALLA, Victor Vincent. A crise de interpretação é nossa: procurando compreender a fala das classes subalternas. Revista Educação \& Realidade. Porto Alegre: Universidade Federal do Rio Grande do Sul, v. 21, n. 2, p. 177-190, 1996.

VASCONCELOS, Eymard Mourão. Redefinindo as práticas de saúde a partir de experiências de educação popular nos serviços de saúde. Interface - Comunicação, Saúde, Educação, v. 5, n. 8, p. 121-126, 2001.

VELHO, Gilberto. Biografia, trajetória e mediação. In: VELHO, Gilberto; KUSCHNIR, 
Karina (Orgs.). Mediação, cultura e política.

Rio de Janeiro: Aeroplano Editora, p. 14-28, 2001.

Recebido em 07/05/2008

Aprovado em 11/10/2008 

